\title{
Processo Coletivo de Reformulação Curricular do BCC-IME-USP ${ }^{1}$
}

\author{
Daniel Macêdo Batista^*, Giuliano Salcas Olguint, Jackson José de Souza^, \\ José Coelho de Pina^, Pedro Paulo Vezzá Campos` e William Alexandre Miura Gnann^ \\ •Departamento de Ciência da Computação do Instituto de Matemática e Estatística da Universidade de São Paulo \\ †Faculdade de Educação da Universidade Estadual de Campinas \\ * Autor para correspondência: batista@ime.usp.br
}

\begin{abstract}
RESUMO
A última reformulação na grade curricular do bacharelado em Ciência da Computação (BCC) do IME-USP deu-se em 1998. Há seis anos, um grupo de alunas, alunos, ex-alunas, ex-alunos, professoras e professores do BCC iniciou um estudo com o objetivo de propor atualizações para a grade curricular do curso. Entre as principais mudanças propostas por este grupo estão a criação de trilhas e o aumento do número de disciplinas optativas eletivas, permitindo, inclusive, que os alunos cursem mais disciplinas de outras áreas e mesmo de outras universidades. Neste texto, apresentamos o processo de mudança da grade, a nova grade curricular, bem como as diferenças entre as estruturas curriculares antiga, anterior e nova. A nova grade curricular entrou em vigor no ano de 2016. É importante observar que o processo contou fortemente com a participação de alunas, alunos, ex-alunas e ex-alunos. Um efeito colateral positivo dessa participação é o aumento do envolvimento das alunas e dos alunos no curso, que pode ser observado pela criação espontânea de diversos grupos de atividades extracurriculares.
\end{abstract}

Palavras-chave: Ciência da Computação; Reforma Curricular; Alumni.

\begin{abstract}
The last curriculum reform of the undergraduate degree Program in Computer Science (BCC) of the IME-USP took place in 1998. Six years ago, a group of BCC students, alumni, and professors began a study aiming to propose updates to the BCC curriculum. Among the main changes proposed by this group are the creation of tracks and the increase in the number of elective courses, allowing students to attend more courses from other areas and even from other universities. In this paper we present the update process of the curriculum, the new curriculum, as well as the differences between old, previous and new curricula. The new curriculum became valid in 2016. It is important to note that the process relied on the participation of students and former students. A positive side effect of this participation is the increase of the students' involvement in the Program, which can be observed by the spontaneous creation of various extracurricular activities groups.
\end{abstract}

Keywords: Computer Science; Curriculum Reform; Alumni.

\section{Introdução}

Na década de 1990, os cursos de graduação em Computação eram basicamente de Ciência da Computação (CG), com ênfase em software, e Engenharia da Computação, com ênfase em hardware. No início dos anos 2000, essa divisão deixou de ser bicromática, e vários outros cursos surgiram para atender um espectro bem maior de necessidades e de adequação à expansão da computação (CS, 2001). Essa tendência policromática continuou (CS, 2005). Novos pensamentos e novas tecnologias têm alterado a compreensão da sociedade acerca dos conhecimentos fundamentais de um cientista da computação.

A dinâmica das mudanças em computação indica que grades curriculares, ou simplesmente grades, em CG devem ser continuamente monitoradas num ciclo de atualizações. Em conjunto, a grande quantidade de especialidades da computação e a interdisciplinaridade da área sugerem estruturas que sejam flexíveis e que possam ser rapidamente atualizadas. Dessa forma, estudantes de CG terão 
a possibilidade de decidirem o caminho de estudo a ser trilhado (CS, 2013) e se desenvolverem naqueles tópicos em que tenham maior interesse e aptidão. Além disso, é importante que o curso forme cidadãs e cidadãos com senso crítico e com consciência.

Entidades que sugerem modelos de grades para CG como a Association for Computing Machinery (ACM), o Institute of Electrical and Electronics Engineers (IEEE) e a Sociedade Brasileira de Computação (SBC) têm apontado para a importância de diminuir a quantidade de disciplinas obrigatórias, permitindo o surgimento e desaparecimento de disciplinas especializadas que garantam que mudanças nas tendências da computação não tornem uma grade obsoleta (CS, 2013). A relevância de grades flexíveis, não só em cursos de CC, foi um dos tópicos abordados em entrevistas e no discurso de posse do atual reitor da Universidade de São Paulo (USP) (HEBMÜLLER, 2014). Esse também foi o tema de um simpósio organizado pela Fundação de Amparo à Pesquisa do Estado de São Paulo (Fapesp) (Alisson, 2014) no início de 2014. A principal característica da nova grade para o BCG é a sua flexibilidade.

Relatos de experiência sobre reformulações de grades curriculares têm sido frequentes (LEITE et al., 2013; SETTI et al., 2014). Em Setti et al. (2014), os autores centram-se numa das principais motivações para a mudança curricular: a evasão. No nosso caso, o foco é no processo de reformulação da grade, que contou com a participação de diversos docentes, estudantes e egressos do BCC. O foco em Leite et al. (2013), é na apresentação da grade e das ênfases. No nosso caso, a nova grade apresenta o que chamamos de núcleo, com as disciplinas mais básicas, porém as alunas e os alunos ainda precisam cursar a carga horária mínima exigida pelo MEG para a obtenção do diploma de bacharel em Ciência da Computação. O processo realizado contou fortemente com a participação de alunas, alunos, ex-alunas e ex-alunos, o que tem levado a consequências positivas que serão comentadas no decorrer deste texto. A reformulação do BCG é baseada na escolha de trilhas por parte das alunas e dos alunos, sendo que não há a obrigação de escolher uma ênfase para concluir o curso. Todos os detalhes do processo de reformulação estão relatados no documento "Reformulação do BCG-IME-USP" (LOSNAK et al., 2014).

\section{Breve Histórico e Motivação}

Em 2014, o BCC-IME-USP completou quarenta anos. Nesse tempo o curso formou pouco mais de 1350 bacharéis em Ciência da Computação. Segundo uma pesquisa realizada com ex-alunas e ex-alunos do BCG em 2012, 86\% trabalham com computação e 13\% não trabalham mais na área (LOSNAK et al., 2014). Esses bacharéis estão espalhados nas mais diversas atividades. São professoras, professores, pesquisadoras e pesquisadores em universidades, centros de pesquisa e empresas (Facebook, Fatec, Google, IBM Watson, IBM Research - Brasil, ITA, Microsoft, Queen's University, UFABC, UFF, Unicamp, Universidade Mackenzie, USP, Texas A\&M University, Universidad Adolfo Ibanezm etc.). Há também egressos que criaram suas próprias empresas (Alora, Caelum, Kekanto, Playax, Scipopulis etc.). No que diz respeito à modificação da grade do curso, não foram removidas a base teórica e a grande fluência em programação, que são apontadas por egressos como uma das suas qualidades no exercício da profissão (RIBEIRO-NETO, 2015).

Em 1998, ocorreu a última reforma da grade do BCG (FERREIRA \& SILVA, 1999), que passou por pequenas alterações (apenas duas disciplinas obrigatórias foram trocadas de semestre), mas se manteve essencialmente a mesma até 2015. Há cerca de seis anos, em uma reunião entre alunas, alunos, professoras e professores, foi sugerido que a grade do BCG deveria ser revista. Assim, no início de 2011, a Comissão de Coordenação do BCG (CoG) criou o Grupo Apoio ao BCG com o objetivo de, entre muitos outros, produzir informações e sugestões para auxiliar o conselho do Departamento de Ciência da Computação (DCG) na reformulação da grade. Esse grupo, que existe até hoje, é formado por alunas, alunos, professoras e professores do BCG. Foi então que teve início o 
processo de elaboração de uma proposta de grade para o BCG.

Neste texto, fazemos referências a três grades do BCG-IME-USP: a em vigor até 1997, a qual chamamos de grade antiga (BCC 1997); a em vigência a partir de 1998 até 2015, à qual nos referimos como grade anterior (BCC 2014); e, finalmente, a que entrou em vigor em 2016 e que chamamos de grade nova (BCC 2016). Todas essas grades e outras informações sobre o BCC-IME-USP estão disponíveis na página http://bcc.ime.usp.br.

\section{Processo}

A seguir descrevemos alguns dos vários elementos que fizeram parte do processo de elaboração da grade nova. Entre esses elementos estão: avaliações do curso feitas pelas alunas e pelos alunos semestralmente; pesquisa com ex-alunas e ex-alunos; reuniões abertas entre alunas, alunos, professoras e professores; estudo de grades de BCCs no Brasil e em outros países; apresentações de diretrizes curriculares (SBC, 2005; CS, 2001; CS, 2005; CS, 2013); e pesquisa sobre o núcleo de disciplinas para a grade. As opiniões de alunas, alunos, ex-alunas, ex-alunos, professoras e professores e uma visão geral dos cursos de CG foram os ingredientes da nova grade.

\section{Avaliações do BCC}

Desde 2009 realiza-se no BCC uma consulta discente de ensino. Esse processo, que foi desenvolvido e implementado pela Escola Politécnica da USP, não tem como objetivo controlar o andamento das aulas ou os docentes. Fundamentalmente, o processo promove a discussão sobre a qualidade do curso (aulas, material didático, integração das disciplinas de um mesmo semestre, entre outros) e detecta eventuais falhas nos conteúdos curriculares e na inter-relação entre as disciplinas dos diversos semestres do BCC. Nesse processo, alunas e alunos que se voluntariam a ser representantes de classe (RCs) elaboram um questionário, juntamente com um orientador pedagógico, que é posteriormente respondido pelas alunas e pelos alunos do BCC. Após a compilação das respostas, são realizadas reuniões entre RCs, professoras, professores, representantes da CoC e um orientador pedagógico. Com isso foi criado um banco de dados sobre a qualidade de oferecimento das disciplinas e estabeleceu-se uma rotina de discussão de problemas e possíveis soluções. O projeto da grade nova para o BCG foi enormemente influenciado por essas avaliações e reuniões. Por exemplo, a partir dessas avaliações foi possível constatar a falta na grade anterior de uma disciplina de Vetores e Geometria no primeiro semestre. Essa disciplina ajudaria no aprendizado de Cálculo II e Álgebra Linear, disciplinas do segundo semestre da grade.

\section{SBC e as Grades de BCCs}

Inicialmente, em 2011, a grade anterior foi avaliada sob a óptica das recomendações do Currículo de Referência da SBC (SBC, 2005) e seus núcleos. Em seguida, o mesmo foi feito sob a óptica de outros BCAs no Brasil. A partir disso, em maio de 2011, foi gerado o documento Currículo de Referência da SBC e a Grade Curricular do BCC (LOSNAK et al., 2014), cuja intenção foi buscar inspiração observando os modelos e ideias de grades adotadas por outros BCCs no Brasil. Encontramos várias propostas interessantes e algumas estão presentes na grade nova.

Por exemplo, a partir desse documento foi possível observar que em relação a outros BCCs, no tocante às disciplinas obrigatórias, a grade anterior possui: poucos créditos em disciplinas obrigatórias; poucos créditos no núcleo de Contexto Social e Profissional; e muitos créditos (no mínimo 37\% a mais e no máximo 138\% a mais) no núcleo de Matemática. Além disso, o BCG faz parte de um grupo de três a cinco outros BCCs que têm poucos créditos no núcleo Fundamentos da Computação e de Tecnologia da Computação. É evidente que esse fato ou sua alteração ao longo dos anos estão relacionados com o perfil do corpo docente.

Levando em consideração os dados levantados por esse documento, alunas, alunos, professoras e professores do BCG fizeram várias considerações e sugestões que posteriormente foram inseridas no mesmo (LOSNAK et al., 2014). 


\section{Pesquisa com Ex-Alunos}

Em agosto de 2012, iniciou-se o processo de contatar ex-alunas e ex-alunos do BCG para participarem de uma pesquisa (LOSNAK et al., 2014). Um dos objetivos da pesquisa foi receber das ex-alunas e dos ex-alunos as suas críticas, sugestões e opiniões sobre o BCG para a criação de disciplinas e outras mudanças curriculares. Participaram aproximadamente 260 ex-alunas e ex-alunos de um total de cerca de 1200 .
Os resultados dessa pesquisa têm fornecido elementos para as tomadas de decisões sobre a grade nova. Por exemplo, na pesquisa as ex-alunas e os ex-alunos classificam os conhecimentos adquiridos no BCG em termos de quão úteis foram para as suas atividades profissionais. As opções dadas foram: "muito", "mais ou menos", "pouco" ou "nada útil", e o resultado geral está a seguir, de acordo com uma divisão em núcleos baseada no Gurrículo de Referência da SBC (SBC, 2005).

\begin{tabular}{|c|c|c|c|c|c|}
\hline & \multicolumn{4}{|c|}{ Utilidade (\%) } & Não \\
\hline Núcleo & muito & $\begin{array}{c}\text { mais ou } \\
\text { menos }\end{array}$ & pouco & nada & $\begin{array}{c}\text { Respondeu } \\
\text { (\%) }\end{array}$ \\
\hline BCC como um todo & 68,7 & 26,8 & 3,4 & 0,0 & 1,1 \\
\hline Matemática & 32,1 & 37,7 & 26,0 & 3,4 & 0,8 \\
\hline Probabilidade e Estatística & 30,2 & 36,6 & 26,0 & 6,0 & 1,1 \\
\hline Fundamentos da Computação & 59,6 & 28,3 & 10,9 & 0,0 & 1,1 \\
\hline Tecnologia da Computação & 68,7 & 21,5 & 7,2 & 1,1 & 1,5 \\
\hline Física & 4,2 & 18,1 & 35,8 & 40,4 & 1,5 \\
\hline
\end{tabular}

Tabela 1 - Resultado da pesquisa com ex-alunas e ex-alunos do Bacharelado em Ciência da Computação (BCC).

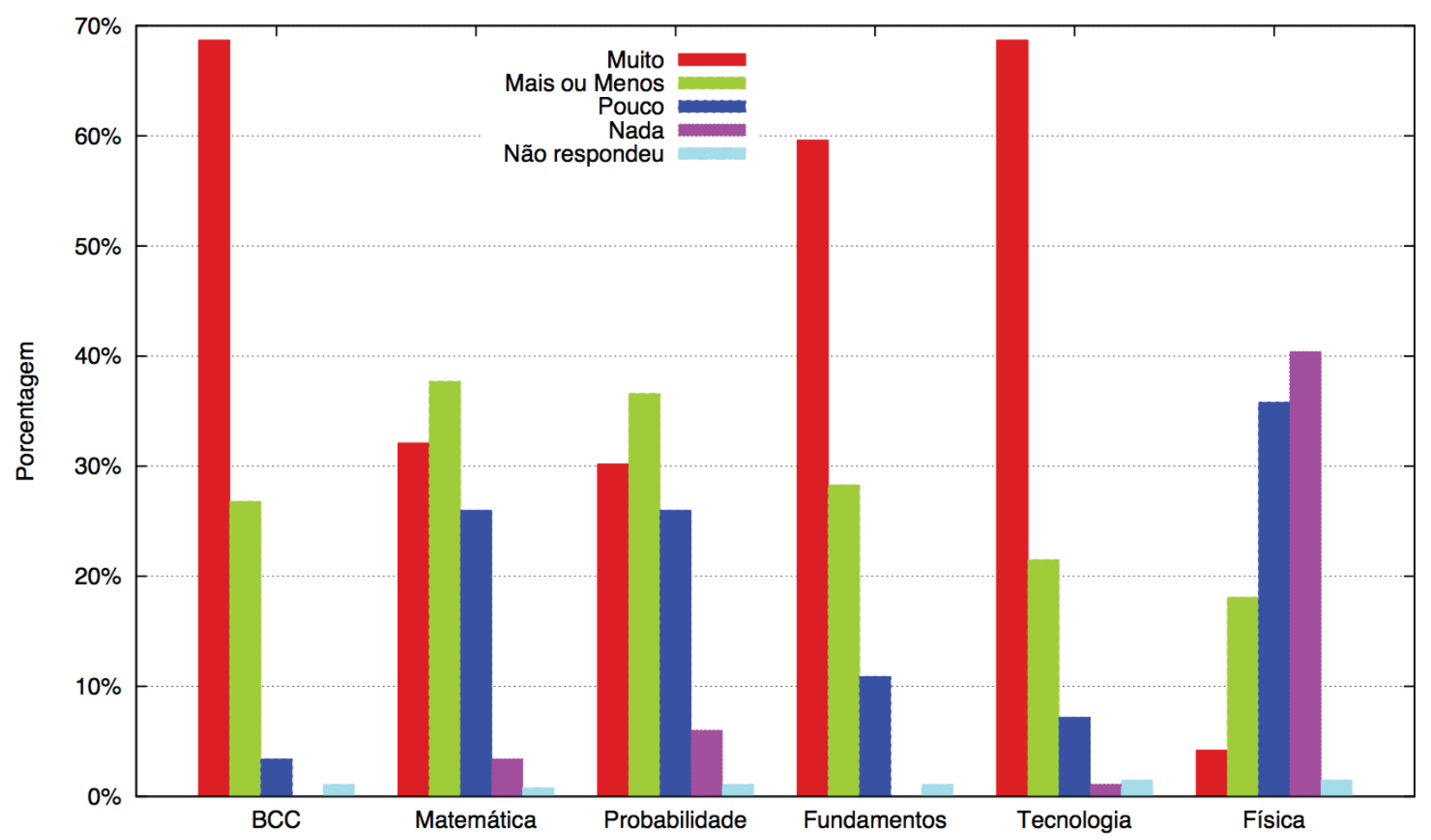

Figura 1 - Gráfico com os resultados da pesquisa com ex-alunas e ex-alunos do BCC. 
Como exemplo de mais um dos resultados da pesquisa, vale mencionar que verificamos que, ao longo dos quarenta anos do BCG, a disciplina Estrutura de Dados foi considerada relevante para a carreira profissional pela grande maioria dos ex-alunos. Também se observou que determinadas disciplinas foram apontadas como mais importantes pelos ex-alunos de acordo com o período de graduação deles. Isso é esperado, tendo em vista a evolução da CC e as mudanças na grade. Por exemplo, entre as disciplinas consideradas muito relevantes pelos ex-alunos nos anos 1970 e 1980, estavam Projeto de Compiladores e Sistemas Operacionais; no final dos anos 1990 destaque para Sistemas de Bancos de Dados; e, mais recentemente, aparece Laboratório de Programação eXtrema. Dados como esses mencionados e muitos outros enriqueceram sobremaneira a discussão da grade nova.

É importante observar que toda a comunidade do BCG-IME-USP participou ativamente da definição de metas e no projeto de implementação das ações, que se traduz na nova grade curricular.

\section{Reuniões Abertas}

De 2012 a 2015 o Grupo Apoio ao BCC organizou reuniões para a elaboração da nova grade para o BCC. Essas reuniões ocorreram regularmente no período de aulas, tipicamente a cada duas semanas, das 12 horas às 13 horas. Até abril de 2014 foram realizadas aproximadamente trinta reuniões. Acreditamos que o fato de as reuniões terem sido feitas no horário do almoço e com a duração fixa de no máximo uma hora colaborou para que elas não se esvaziassem.

Nessas reuniões, para subsidiar as discussões, foram apresentadas várias grades, modelos de currículos, diretrizes curriculares, resultados de pesquisas, sugestões de disciplinas, sugestões de modelos de currículos e conversas com professoras e professores convidados de outros cursos.

As reuniões foram abertas, amplamente divulgadas e contaram com a participação de alunas e alunos dos diversos anos do curso, especialmente RCs, ex-alunas e ex-alunos que cursam pós-graduação, professoras e professores. O número de participantes

\section{Estruturas de Dados Introdução à Teoria do Grafos programação} Projeto de Complladores Sistemas Operacionais pedes "Construção de Montadores Álgebra Linear para Computação Ẫ gebra Booleana e Aplicações Laboratório de Programação | Introdução à Computação Princípios de Desenvolvimento de Algoritmos Introdução à Teoria da Computabilidade aprender Linguagens Formais e Autômatos

Figura 2 - Nuvem com as palavras mais citadas pelas ex-alunas e pelos ex-alunos do período entre 1984-1998 na pesquisa aqui apresentada.

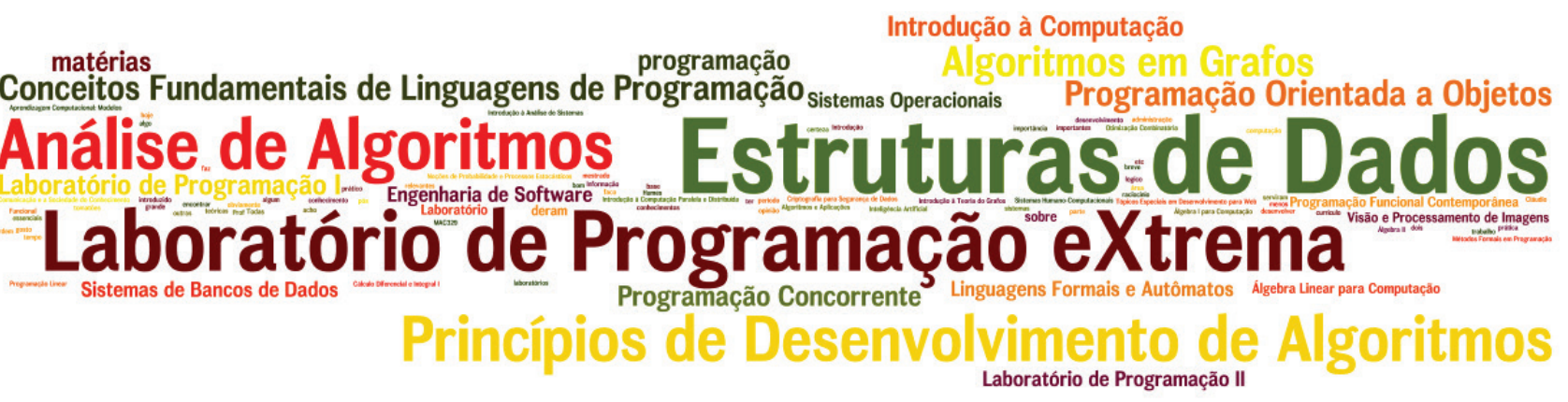

Figura 3 - Nuvem com as palavras mais citadas pelas ex-alunas e pelos ex-alunos do período entre 2009-2013 na pesquisa aqui apresentada. 
variou de dez a trinta, dependendo do período do ano. Os relatos de todos os encontros foram também amplamente divulgados e estão disponíveis a partir da página do BCC.

Vale salientar que, nessas reuniões, as alunas, os alunos, as ex-alunas e os ex-alunos tiveram uma participação fundamental, já que possuem uma visão geral, ampla e atual do andamento de cada disciplina e do curso como um todo. Informações importantes como relações entre disciplinas listadas como pré-requisitos e cumprimento da ementa por parte das professoras e dos professores são exemplos de dados que fazem parte do dia a dia acadêmico das alunas e dos alunos e que seriam ignorados caso eles não participassem das reuniões.

\section{Pesquisa para Determinação do Núcleo}

Durante as reuniões abertas foi decidido que, por causa da grande quantidade de especializações possíveis, a grade nova seguiria um modelo com trilhas de conhecimento. Dessa forma, ficou acordado que um núcleo das disciplinas obrigatórias do curso deveria ser definido. Esse núcleo seria formado pelas disciplinas que as alunas, os alunos, as ex-alunas, os ex-alunos, as professoras e os professores considerassem relevantes para a maioria das trilhas ou que fossem consideradas indispensáveis na formação de cientistas da computação. Para isso, foram preparados questionários, um para cada par de áreas (knowledge areas) da planilha de habilidades (outcomes) utilizada pela ACM/IEEE no seu projeto de currículo de referência (CS, 2013). Alunas, alunos, ex-alunas, ex-alunos, professoras e professores responderam os questionários. Os resultados dessa pesquisa estão disponíveis na página do BCC.

\section{Objetivos e Princípios}

Idealmente, gostaríamos que a grade fornecesse elementos para preparar cientistas da computação responsáveis, engajados socialmente e conscientes da ampla relação da computação com os mais diversos domínios do conhecimento.

Depois de dez reuniões abertas, foram apresentados ao conselho do DCG os princípios que 132 nortearam a grade nova. Dentre esses princípios, os fundamentais estão a seguir.

O tamanho do núcleo da grade formado por disciplinas obrigatórias deveria ser pequeno. Enquanto o leque de tópicos relevantes cresceu, a duração da graduação permaneceu constante. Dessa forma, a nova estrutura curricular deveria conter os tópicos imprescindíveis a quem quer seguir trabalhando ou estudando na área. Um número pequeno de disciplinas obrigatórias garante que mudanças nas tendências da computação não tornem a grade defasada rapidamente. Enquanto isso, o surgimento e o desaparecimento de disciplinas especializadas garantem que ela permaneça atualizada.

A grade deveria ser flexível o suficiente para permitir que as alunas e os alunos trabalhassem em diversas áreas. A CG é um campo vasto que interage e faz uso de diversos conceitos provenientes de Matemática, Engenharia, Psicologia, Estatística, Artes, Linguística, Ciências Naturais, entre outros. Durante a graduação, as alunas e os alunos devem criar uma desenvoltura para trabalharem entre essas diversas disciplinas. Isso pode ser realizado aproveitando a grande variedade e qualidade de disciplinas que as demais unidades da USP oferecem.

Um sistema de trilhas, ênfases ou módulos seria interessante para nortear os estudos das alunas e dos alunos. Esse princípio tem como efeito colateral mostrar a riqueza da CG como área de estudo, tornando a graduação mais atrativa a novas alunas e novos alunos. Cada trilha, ênfase ou módulo deveria agrupar as disciplinas relacionadas com uma determinada área da CC, de modo a auxiliar as alunas e os alunos interessados em se especializarem naquela área.

\section{Grades Antiga, Anterior e Nova}

A grade anterior possuía uma grande qualidade, que era a responsável pelo fato de o BCC não se ter tornado um curso obsoleto: oferecia 38 créditos em disciplinas optativas, distribuídos em 32 de optativas eletivas e 6 créditos em optativas livres.

Optativas eletivas são disciplinas dentro de um conjunto preestabelecido, tipicamente disciplinas 
relacionadas com computação e em sua maioria oferecidas pelo próprio DCG do IME-USP. As optativas livres não têm preestabelecimento do seu conjunto e na grade anterior são, preferencialmente, disciplinas com um caráter de humanidades. Já na grade nova, optativas livres são livres na acepção da palavra, pois podem ser qualquer disciplina da USP, inclusive da lista de eletivas, e possivelmente de outras universidades.

Como cada disciplina costuma ter quatro créditos, na grade anterior as alunas e os alunos deveriam cursar cerca de oito disciplinas optativas eletivas e duas optativas livres. Essa carga em disciplinas optativas correspondia a cerca de $20 \%$ do curso. Na grade antiga esse valor era de aproximadamente $16 \%$. Na grade nova essa porcentagem de disciplinas optativas é de quase $40 \%$. O propósito desse aumento em disciplinas optativas é flexibilizar o BCG.

A seguir apresentamos uma tabela, e o gráfico correspondente, que comparam as grades antiga, anterior e nova. As disciplinas obrigatórias estão organizadas segundo a classificação de núcleos da
SBC (SBC, 2005).

Levando em consideração o número de créditos em disciplinas optativas, vê-se que a grade nova é muito mais flexível que as suas antecessoras. Esperamos com isso dar a oportunidade de as alunas e os alunos entrarem em contato com disciplinas de outros cursos como Química, Física, Biologia, Ciências Sociais, Economia, entre outros. Para que esse contato se efetive, a CoC trabalha no sentido de as escolas, faculdades e institutos da USP abrirem vagas para alunas e alunos do BCC.

Comentamos agora acerca de algumas disciplinas que foram criadas a fim de implementarem os objetivos e princípios delineados. A disciplina Integração na Universidade e na Profissão tem a missão de apresentar o BCG, o IME e a USP às calouras e aos calouros. Além disso, essa disciplina é um lugar onde as alunas e os alunos podem constituir grupos de interesse e estender seus horizontes dentro do DCG. Essa disciplina é inspirada nas disciplinas Introdução à Ciência da Computação, da Universidade Federal de Minas Gerais, Introdução à Computação, da Universidade Federal de Santa

\begin{tabular}{|c|c|c|c|c|c|c|}
\hline & \multicolumn{5}{|c|}{ Grade } \\
\hline & \multicolumn{2}{|c|}{ Antiga } & \multicolumn{2}{|c|}{ Anterior } & \multicolumn{2}{c|}{ Nova } \\
\hline Núcleo & créditos & $\%$ & créditos & $\%$ & créditos & $\%$ \\
\hline Créditos em optativas & 27 & 15,9 & 38 & 19,1 & 76 & 39,0 \\
\hline Créditos trabalho & 10 & 5,8 & 24 & 12,1 & 24 & 12,3 \\
\hline Contexto Social e Profissional & 3 & 0,1 & 3 & 0,1 & 7 & 3,6 \\
\hline Matemática & 50 & 29,4 & 50 & 25,1 & 36 & 18,5 \\
\hline Tecnologia da Computação & 36 & 21,2 & 40 & 20,1 & 32 & 16,4 \\
\hline Ciências básicas & 20 & 11,7 & 32 & 16,1 & 16 & 8,2 \\
\hline Sistemas de Informação & 24 & 14,1 & 12 & 6,0 & 4 & 2,1 \\
\hline Total & 0 & 0 & 0 & 0 & 0 & 0 \\
\hline
\end{tabular}

Tabela 2 - Comparação das grades do BCC. 


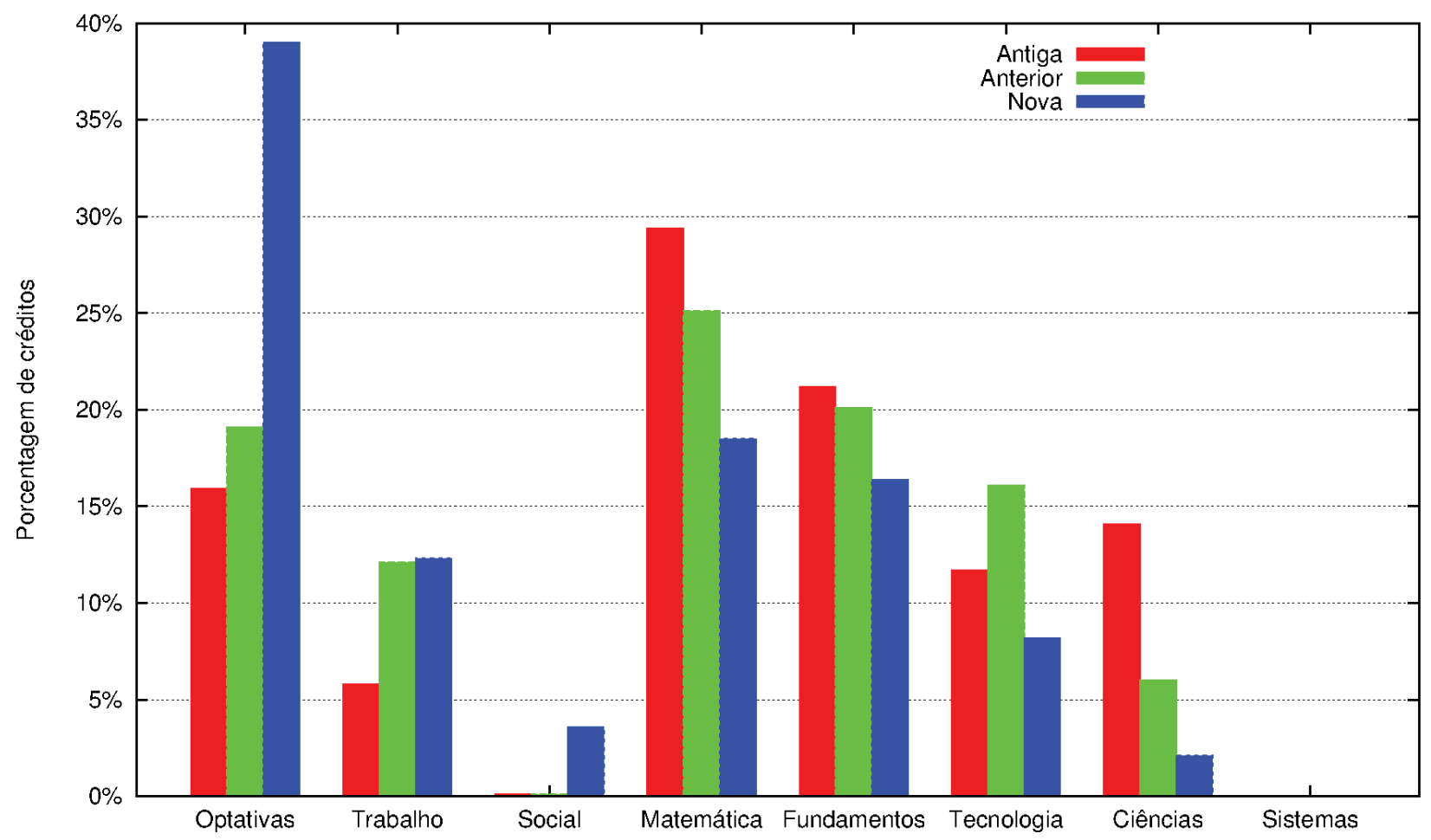

Figura 4 - Gráfico com a comparação das grades do BCC.

Catarina, e Freshmen Immigration Course e Great Theoretical Ideas in Computer Science, da Carnegie Mellon University.

Tendo em vista que quase $40 \%$ dos créditos da grade nova são em disciplinas optativas e o modelo adotado foi o de trilhas, em que as alunas e os alunos podem seguir diversos caminhos, foi criada a disciplina Caminhos no bacharelado em Ciência da Computação, com objetivo de, no início do segundo ano, orientar as alunas e os alunos sobre as várias possibilidades de formação no BCG através de suas trilhas.

A fim de incentivar o desenvolvimento das alunas e dos alunos como indivíduos e cidadãos, foi criada a disciplina optativa eletiva Atividade Curricular em Comunidade. Essa disciplina é uma reprodução da disciplina Ação Curricular em Comunidade e em Sociedade oferecida pela Universidade Federal da Bahia.

Também foram criadas disciplinas optativas para estimular as alunas e os alunos a se empenharem em alguma atividade independente, como o USPGameDev, o Hardware Livre, o MaratonIME, o IME Workshop, e terem contato com atividades de pesquisa. São elas a Atividade Curricular 134 em Cultura e Extensão e a Atividade Curricular em Pesquisa.

As professoras e os professores do DCG sugeriram, até o momento, quatro trilhas: Algoritmos e Complexidade, Sistemas de Software, Inteligência Artificial e Ciência de Dados. Essas trilhas são fortemente influenciadas pelo perfil do corpo docente do DCG.

\section{Expectativas e Lições Aprendidas}

Esperamos que a grade nova facilite a atualização constante do BCC, de modo a acompanhar os avanços em CG. Além disso, desejamos formar cientistas da computação mais responsáveis, já que, com o modelo de trilhas e a grande quantidade de optativas, os alunos precisarão ser capazes de tomar seus próprios caminhos. Esperamos ainda que a interdisciplinaridade motivada pela grade nova faça com que os formandos e as formandas do BCG colaborem nos avanços da área.

A CoC do BCG deve trabalhar para que as Escolas, Faculdades e Institutos ofereçam disciplinas livres para as alunas e para os alunos do BCG. Além disso, a CoC deve estar atenta para possíveis problemas com a grade nova. Ambas as tarefas 
serão facilitadas através das consultas discentes de ensino que se realizam em todo semestre. É importante observar que muitas das nossas expectativas podem não se concretizar. Entretanto, mantendo as consultas constantes no curso e o contato com ex-alunas, ex-alunos, e com suas empregadoras e seus empregadores, esperamos fazer correções na grade em intervalos de tempo menores do que os dezessete anos para a mudança atual.

Se fôssemos indagados sobre qual o componente mais importante em todo esse processo de reformulação da grade, nós responderíamos que foi a participação das alunas, dos alunos, das ex-alunas e dos ex-alunos nas reuniões abertas. Acreditamos que o processo de reformulação participativo junto com as consultas discentes de ensino tem encorajado o envolvimento das alunas e dos alunos com o curso. Isso pode ser visto com a multiplicação de ações espontâneas de criação de grupos de extensão como USPGameDev, Hardware Livre, IME Workshop, Rede Linux, MaratonIME, Encontro do BCG, CGSL, entre outros.

\section{Agradecimentos}

Esta reformulação curricular não teria sido possível sem a colaboração abnegada de alunas, alunos, ex-alunas e ex-alunos do curso que participaram das reuniões, prepararam documentos e apresentações, preencheram questionários, estudaram grades curriculares etc. A todos os participantes, os mais sinceros agradecimentos do DCG, das futuras alunas e dos futuros alunos do BCC que desfrutarão desse novo currículo.

Entre as professoras e os professores de fora do DCG que gentilmente colaboraram com a elaboração da grade proposta estão Adilson Simonis (MAE-IME-USP), Antônio Carlos Pedroso de Lima (MAE-IME-USP), Beatriz Daruj Gil (FFLGH-USP), Carlos Alberto de Bragança Pereira (MAE-IME-USP), Elisabeti Kira (MAE-IME-USP), Lucia Pereira Barroso (MAE-IME-USP), Lucia Satie Ikemoto Murakami (MAT-IME-USP) e Vitor de Oliveira Ferreira (MAT-IME-USP).

O DCG também agradece à senhora Elaine Cristina da Silva, do Serviço de Assistência à
Graduação da Pró-Reitoria de Graduação, a orientação durante o processo de elaboração da nova grade curricular. A presteza das secretárias do DCG, Adenilza Aparecida Alves, Ana Carla de Souza e Edna Brisolla de Campos Torres, foi fundamental durante todo o processo. Também somos muito agradecidos ao Programa Ensinar com Pesquisa da Pró-Reitoria de Graduação da USP e ao IME-USP pelo apoio financeiro.

\section{Nota}

1 Uma versão deste artigo foi publicada nos anais do $23^{\circ}$ WEI - Congresso da SBC, 2015.

\section{Observações}

Os autores Jackson José de Souza e Pedro Paulo Vezzá Campos foram financiados pelo Programa Ensinar com Pesquisa da Pró-Reitoria de Graduação da USP e pelo IME-USP.

\section{Referências Bibliográficas}

ALISSON, E. "Especialistas Defendem Currículo mais Flexível nas Universidades". Agência Fapesp, 2014. Disponível em: http://agencia.fapesp.br/18575. Acessado em 6 fev. 2014.

BCC. "Grade Curricular do BCG-IME-USP para 1997", 1997. Disponível em: http://bcc.ime.usp.br/ curriculo1997/.

BCC. "Grade Curricular do BCG-IME-USP para 2014", 2014. Disponível em: http://bcc.ime.usp.br/ curriculo2014/.

BCC. "Grade Curricular do BCG-IME-USP para 2016", 2016. Disponível em: http://bcc.ime.usp.br/ curriculo2016/.

CS. "Computing Curricula 2001: Computer Science", 2001. Disponível em: http://www.acm.org/ education/education/education/curric_vols/cc2001. pdf. Acessado em 7 fev. 2014.

CS. "Computing Gurricula 2005: The Overview Report", 2005. Disponível em: http://www.acm. org/education/education/curric_vols/CC2 005 March06Final.pdf. Acessado em 7 fev. 2014.

CS. "Computer Science Curricula 2013: Curriculum Guidelines for Undergraduate Degree Programs in Computer Science". Disponível em: http://www.acm.org/education/CS2013-final-report. pdf. Acessado em 7 fev. 2014.

FERREIRA, C. E. \& SILVA, D. M. da. "O Novo BCC da USP: um Novo Curso para os Desafios 
do Novo Milênio". Anais do WEI - XIX Congresso da Sociedade Brasileira de Computação, Rio de Janeiro, 1999, pp. 505-514.

HEBMÜLLER, P. "Reforma do Ensino de Graduação Será Meta Prioritária". Fornal da USP, 2014. Disponível em: http://espaber.uspnet.usp.br/ jorusp/?p= 33343. Acessado em 7 fev. 2014.

LEITE, J. C.; GOMES, A. V., SILVA, B. S. da \& REGO,J. I. do. "O Curso de Tecnologia da Informação na UFRN". Anais do WEI - XXXIII Congresso da Sociedade Brasileira de Computação, 2013, pp. 701-710.

LOSNAK, A. L. de A; CALÓ, A.; BATISTA, D. M.; OLGUIN, G. S.; SOUZA, J. J. de, PINA, J. C. de; LOURO, R. D. \& GNANN, W. A. M. "Reformulação do BCC-IME-USP", 2014. Disponível em: http://bcc. ime.usp.br/principal/documentos/reformulacao.pdf. Acessado em 14 abr. 2015.
RIBEIRO-NETO, B. "IME: Celeiro de Talentos em Computação", 2015. Disponível em: http://www.ime. usp.br/images/arquivos/aconteceime/acontecenoime_ edicao25.pdf. Acessado em 14 abr. 2015.

Sociedade Brasileira de Computação (SBC). "Currículo de Referência da SBC para Cursos da Graduação em Bacharelado em Ciência da Computação e Engenharia de Computação". Disponível em: http://www.sbc.org.br/documentos-da-sbc/send/131curriculos-de-referencia/760-curriculo-de-referencia-ccec-versao2005. Acessado em: 14 abr. 2015.

SETTI, M. G.; EMER, M. G. F. P.; AMARAL, M. A.; MERKLE, L. E. \& GONÇALVES, M. M. "Proposta de Flexibilização Curricular do Curso de Sistemas de Informação Ofertado pela UTFPRCuritiba". Anais do WEI - XXXIV Congresso da Sociedade Brasileira de Computação, 2014, pp. 1366-1375.

Publicado em 31/03/2017. 